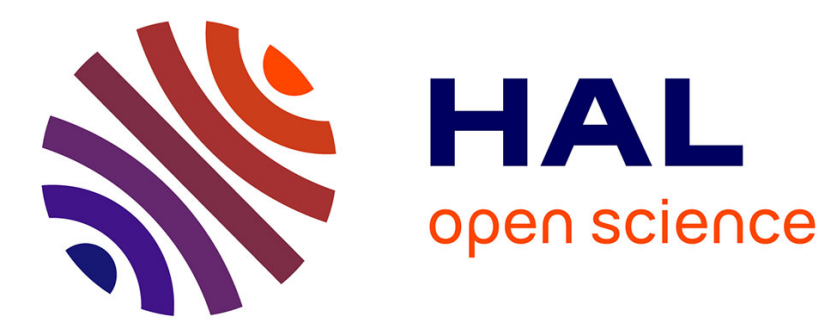

\title{
Root foraging capacity depends on root system architecture and ontogeny in seedlings of three Andean Chenopodium species
}

Ricardo Alvarez-Flores, Thierry Winkel, Anh Nguyen-Thi-Truc, Richard Joffre, R Alvarez, Nguyen-Thi-Truc -R Joffre

\section{To cite this version:}

Ricardo Alvarez-Flores, Thierry Winkel, Anh Nguyen-Thi-Truc, Richard Joffre, R Alvarez, et al.. Root foraging capacity depends on root system architecture and ontogeny in seedlings of three Andean Chenopodium species. Plant and Soil, 2014, 10.1007/s11104-014-2105-x . ird-02381068v2

\section{HAL Id: ird-02381068 https://hal.ird.fr/ird-02381068v2}

Submitted on 27 Nov 2019

HAL is a multi-disciplinary open access archive for the deposit and dissemination of scientific research documents, whether they are published or not. The documents may come from teaching and research institutions in France or abroad, or from public or private research centers.
L'archive ouverte pluridisciplinaire HAL, est destinée au dépôt et à la diffusion de documents scientifiques de niveau recherche, publiés ou non, émanant des établissements d'enseignement et de recherche français ou étrangers, des laboratoires publics ou privés. 


\section{Root foraging capacity depends on root system architecture and ontogeny in 2 seedlings of three Andean Chenopodium species}

\section{Ricardo Alvarez-Flores, Thierry Winkel, Anh Nguyen-Thi-Truc, Richard Joffre}

5 R. Alvarez-Flores - A. Nguyen-Thi-Truc - R. Joffre

6 CNRS, UMR 5175 Centre d'Écologie Fonctionnelle et Évolutive, F-34293 Montpellier, France

$7 \quad$ T. Winkel $(\bowtie)$

8 IRD, UMR 5175 Centre d'Écologie Fonctionnelle et Évolutive, F-34293 Montpellier, France

9 e-mail: thierry.winkel@ird.fr

Citation

11 Alvarez-Flores R., Winkel T., Nguyen-Thi-Truc A., Joffre R. 2014. Root foraging capacity depends on root system 12 architecture and ontogeny in seedlings of three Andean Chenopodium species. Plant and Soil 380: 415-428. https://doi.org/10.1007/s11104-014-2105-x.

\section{Abstract}

Aims Morphological and ontogenetic variation in root system architecture holds ecological significance, particularly in low-resource habitats where soil rooting is critical for both seedling establishment and water and nutrient uptake. To assess this variation under contrasted agroecological backgrounds, root architecture and rooting patterns were compared in Andean populations of Chenopodium hircinum, Chenopodium pallidicaule and two ecotypes (wet- and dry-habitat) of Chenopodium quinoa.

Methods Seedlings were grown in rhizotrons under controlled water and nutrient availability. Root branching and elongation dynamics were characterized during 6 weeks after germination, while leaf area, above and belowground biomass, and specific root length were determined at the end of the experiment.

Results Despite large differences in aboveground biomass, all populations showed similar herringbone root systems. The dry-habitat $C$. quinoa had generally the highest root trait values, with fast taproot elongation, thick roots and long root segments resulting in high total root length and deep root proliferation.

Conclusion Irrespective of their contrasting agroecological background, the studied chenopods displayed a similar root system topology. However, from very early development stages, they showed differential root foraging patterns with two extremes: fast and vigourous rooting at depth in the dry-habitat $C$. quinoa, and shallow and thin root system in $C$. pallidicaule adapted to shallow-soil and high-altitude habitats.

Keywords Chenopodium quinoa; Chenopodium hircinum; Chenopodium pallidicaule; Ecotypes; Rhizotron; Root traits; Root system topology 
Root system architecture considers the spatial structure, the geometric features and the branching complexity of the roots of whole plants (Fitter 1987). It has profound implications for plant growth and species distribution, enabling individual plants to cope with changing environmental conditions and plant species to thrive in different ecological niches (Lynch 1995; White et al. 2013). Differences in root system architecture are associated with differences in soil resource acquisition, not only between contrasting functional types (Paula and Pausas 2011; Roumet et al. 2006; Taub and Goldberg 1996), but also among genera and species of the same growth form originating from contrasted ecological habitats (Leva et al. 2009). Chenopodium is one of these genera that thrive under strikingly contrasted environments, notably in South America where strong ecological gradients develop from Amazonian or Southern Pacific lowlands of humid climate and nutrient-rich soil up to the Andean highlands of dry and cold climate and nutrient-poor soil (Troll 1968; Di Castri and Hajek 1976). In these highly contrasted habitats, annual chenopods have diversified, some of them as spontaneous chenopods (e.g. C. hircinum Schrad., C. petiolare Kunth, C. carnosolum Moq.), others as cultivated species like quinoa (C. quinoa Willd.) and cañahua (C. pallidicaule Aellen) with many ecotypes (Kühn et al. 1993; Vargas et al. 2011). None of these chenopods show the morphophysiological adaptations typical to dry or saline habitats environments, such as Kranz anatomy, C4 photosynthetic pathway, or succulence (Fuentes-Bazan et al. 2012). For surviving, these plants thus rely on common plant and life-history traits that control the balance between resource capture and resource use, for which root system architecture plays a key role (Singh et al. 2010).

Examining the various patterns of root system branching or topology, theoretical and experimental works suggest that a root system consisting of only a main axis and primary laterals (herringbone topology) would favour nutrient acquisition in low-resource habitats because it minimizes intraplant root competition (Fitter et al. 1991; Taub and Goldberg 1996). Conversely, a dichotomous topology associated with shorter root links (the segments of root between two nodes, or between a node and a root tip) and greater link number, would favour nutrient capture in high-resource habitats (Fitter et al. 1991; Taub and Goldberg 1996). Most chenopods show a herringbone root system (Fitter 1987), but detailed descriptions are lacking to appreciate differences among species or among ecotypes of contrasted habitats. Regarding plant species adapted to cold and high altitude habitats, they might develop a growth syndrome that includes short plant height and high root mass fraction (Poorter et al. 2011). Growing at elevations up to $4.600 \mathrm{~m}$, the small-sized C. pallidicaule is renowned as the hardiest Andean chenopods (Gade 1970) and yet the adaptive value of its morphophysiological traits remains unknown.

In a context of increasing scarcity of agricultural water and nutrients, improved root system functioning could enhance crop productivity while decreasing crop input requirements (De Dorlodot et al. 2007; Lynch and Brown 2012; White et al. 2013). Cultivated chenopod species such as Ch. quinoa and Ch. pallidicaule are promising candidates for exploring plant ideotypes suited to low-input agriculture (Rojas et al. 2009). In fact, since centuries, Andean farmers have selected several tens of local chenopod varieties for their hardiness under harsh climate and poor soil conditions (Bonifacio 2003). As it happened in other crop species (Palta et al. 2011; Wasson et al. 2012), unconscious selection for improved rooting capacity is likely to have occurred in these Andean chenopod crops. Exploring the morphological variation in root architecture, and particularly the contrast between wild and cultivated species, would help testing this hypothesis of unconsciuous selection as well as defining root system ideotypes that optimize soil resource uptake. 
based on one time measurements cannot reveal the full range of plant responses to changing soil conditions (Chesson 2004). In seedlings, in particular, the dynamics of root growth and branching is critical for the successful establishment of the plants and the exploitation of the soil volume, especially in harsh and variable environments where fast and early rooting is vital to capture ephemeral soil nutrients and deep water (León et al. 2011; Padilla and Pugnaire 2007). An important factor for early root vigor is individual seed mass (Richards et al. 2007; White et al. 2013), a trait showing extensive genetic variation, including in chenopods where natural polyploidization and human selection have led to broad variation in seed mass (Bhargava et al. 2007; Fuentes-Bazan et al. 2012).

By means of a rhizotron experiment, the present study addresses the ontogenetic changes in root system architecture of seedlings plants in three Andean Chenopodium species of different agroecological backgrounds. The starting hypothesis is that Chenopodium plants from low-resource habitats have developed root traits that enhance root foraging in deep soil layers. More specifically, it is expected that chenopods from low-resource habitats would have faster root growth at early growth stage and greater root elongation at depth.

\section{Materials and methods}

Study site and plant populations

The study was conducted outdoor under a transparent rain shelter at the CEFE-CNRS experimental field (Montpellier, France, $43^{\circ} 38^{\prime} 19^{\prime}$ 'N, $\left.3^{\circ} 51^{\prime} 46^{\prime \prime} \mathrm{E}\right)$, from the $11^{\text {th }}$ of March to the $22^{\text {th }}$ of April 2011. Four Chenopodium population samples from contrasting habitats were compared: $C$. hircinum and $C$. pallidicaule both from semi-arid highlands with nutrient-poor soils, $C$. quinoa from temperate lowlands with nutrient-rich soils (wet habitat), $C$. quinoa from arid and cold highlands with nutrient-poor soils (dry habitat) (Table 1). C. hircinum is a wild tetraploid species, $C$. pallidicaule is a domesticated diploid, and C. quinoa is a domesticated tetraploid. The wet-habitat $C$. quinoa pertains to the coastal quinoa ecotype of Chile while the dry-habitat $C$. quinoa is representative of the Salar quinoa ecotype of Bolivia. The seeds of C. quinoa and C. pallidicaule were from local landraces without pedigree. They were collected directly at the specified sites, as were the seeds of $C$. hircinum. In the four studied populations, seeds were selected for their size homogeneity and sterilized with sodium hypochlorite $(1 \%)$ for $10 \mathrm{~min}$ before sowing in rhizotrons at $3 \mathrm{~cm}$ depth.

\section{Rhizotrons}

Rhizotrons measuring $85 \times 34$ × $2.3 \mathrm{~cm}$ were made of white PVC plates with a pane of glass on one side. The windowpane was protected from light incidence with a mobile polystyrene plate $1.5 \mathrm{~cm}$ thick. Each rhizotron was filled with $7 \mathrm{~L}$ of a soil substrate humidified at field capacity (see below), sown with two seeds of the same population and then disposed outdoor under a transparent roof for rain protection. The rhizotrons were disposed with a $15^{\circ}$ inclination from the vertical to favor the root growth on the windowpane.

Soil substrate and growth conditions

The soil substrate was composed of $84.5 \%$ of sand, $6.3 \%$ of clay, $4.5 \%$ of silt, $3.1 \%$ of organic matter, with $\mathrm{pH}$ 8.08, CEC Metson $9.02 \mathrm{cmol}+/ \mathrm{kg}$, and C/N 11.2. Prior to the experiment, the substrate was dried and sterilized to $120{ }^{\circ} \mathrm{C}$ for 48 hours. Then, it was humidified using a nutritive solution (N: 16\%, P: $10 \%, \mathrm{~K}: 24 \%, \mathrm{MgO}: 3 \%$, micro-elements: $2.5 \mathrm{~g} / \mathrm{L})$. When the experiment started, rhizotrons were at field capacity $\left(0.12 \mathrm{~cm}^{3} / \mathrm{cm}^{3}\right)$ and no 
more water was applied until the end of the study. Over the course of the experiment, air temperature at $150 \mathrm{~cm}$ height varied between 3.0 and $35.2{ }^{\circ} \mathrm{C}\left(\right.$ mean $\left.=15.5^{\circ} \mathrm{C} \pm 0.1\right)$, soil temperature at $25 \mathrm{~cm}$ depth varied between 4.8 and $35.2{ }^{\circ} \mathrm{C}\left(\right.$ mean $\left.=14.9{ }^{\circ} \mathrm{C} \pm 0.05\right)$, and air relative humidity varied between 30 and $89 \%($ mean $=61 \% \pm 0.5)$. These conditions of temperature and soil humidity grossly satisfied the optimal growth requirements of the studied populations and no sign of plant physiological stress (e.g. leaf wilting, slow plant growth) was detected. Apart from being a convenient substrate in a comparative study under controlled conditions, the sandy substrate fitted the soil conditions commonly experienced by $C$. pallidicaule and the dry-habitat $C$. quinoa in their native highlands. As regards $C$. hircinum and the wet-habitat $C$. quinoa, their natural environments show a range of soil conditions, including sandy ones. The overall satisfactory growth of these plants in the present experiment indicates that they did not suffer any physical or nutritional limitation due to the soil substrate.

\section{Plant sampling and measurements}

Three days after emergence, plants were thinned to one seedling per rhizotron, and five replicate plants per population were followed weekly from 7 to 42 days after sowing (DAS) for non-destructive growth measurements. Root growth of each replicate plant was recorded weekly by tracing on a transparent acetate sheet the root axes visible through the windowpane of the rhizotron. The root system images were then scanned at a resolution of 400 dpi (Acer Scan 300F, 6684 03A) (Fig. 1) and analyzed with the morphological and architectural procedures of the WinRHIZO Pro2009 software (Regent Instruments Inc., Quebec, Canada). The following root traits were calculated: total tip number (TTN), total link number (TLN), total root length (TRL, m) and total root length per link type (see Fig. 2a for a definition of root link types). The number of new lateral roots appearing on the taproot in successive soil layers was also counted each week.

Following Glimskär (2000), two root topological indices were calculated. The topological quotient index (TQI) for individual plants at 42 DAS was calculated as the ratio $\log (\alpha) / \log (\mu)$, with $\alpha$ representing the altitude of the root system (i.e. the number of links of the longest path from the root collar to an external tip) and $\mu$ its magnitude (i.e. the total number of tips in the root system). The topological slope index (TSI) was determined as described by Fitter and Stickland (1991), calculating the slope of the regression of $\log (\alpha) \operatorname{on} \log (\mu)$ for the set of altitude and magnitude values observed in each population during the time of the experiment. Both topological indices vary between 0 and 1, with large values indicative of a more herringbone-like root system with branching mostly confined to the main axis.

By the end of the experiment (42 DAS), after completing the non-destructive root growth measurements, root collar diameter was measured with an electronic caliper (Mitutoyo, Andover, UK) and each individual plant was cut at the level of the root collar. Plant height $(\mathrm{PH}, \mathrm{cm})$ was measured as the length of the main stem from the root collar to the shoot apex. Leaves were separated from the stems, scanned at 400 dpi (CanonScan LIDE 100) and the images were analyzed with the SigmaScan Pro 5 software (Systat Software Inc.) to determine the total leaf area per plant $\left(\mathrm{LA}, \mathrm{cm}^{2}\right)$. Leaves and stems were then oven-dried at $65{ }^{\circ} \mathrm{C}$ for $48 \mathrm{~h}$ before dry mass weighting. The substrate containing the root system was divided into six depth levels $(0-5 \mathrm{~cm}, 5-20 \mathrm{~cm}, 20-35 \mathrm{~cm}, 35-50 \mathrm{~cm}, 50-$ $65 \mathrm{~cm}, 65-80 \mathrm{~cm}$ ) and roots within each layer were washed, separating the roots growing onto the windowpane from those growing inside the substrate. After drying at $65^{\circ} \mathrm{C}$ for 48 hours, root dry mass was determined to calculate: i) the specific root length (SRL, m/g) from the roots growing onto the windowpane, and ii) the root/shoot ratio (R:S, g/g) from the bulk of the root system biomass. 
149 Differences in plant traits among populations were tested using factorial analysis of variance (ANOVA) after log

150 transformation of the data when necessary to meet the normality and homoscedasticity assumptions. To avoid size

151 effects when comparing populations for TTN, TLN, MLL II, MLL EI and MLL EE, analyses of covariance

152 (ANCOVA) were performed, with TRL as the covariate, and testing for a possible interaction between the 153 covariate and the factor "populations". Tukey's HSD post-hoc tests were used to compare population means at $P$ $154<0.05$. The dependence between selected variables was determined using Pearson's correlation analysis. Statistical 155 procedures were performed using STATISTICA v.7.1 (Statsoft Inc., Tulsa, USA).

\section{Results}

157 Plant size, biomass production and root/shoot ratio

158 Seedlings of dry-habitat $C$. quinoa showed the most vigorous growth, resulting in higher plant height and deeper 159 root system during the course of the experiment, and higher leaf area, root collar diameter and biomass production 160 at 42 DAS (Table 2). At that time, C. pallidicaule, the least vigorous of the studied populations, was only $6.5 \%$ 161 the size of dry-habitat C. quinoa in terms of total plant mass, $10 \%$ its size in terms of leaf area, and $20 \%$ its size in 162 terms of total root length. $C$. hircinum and wet-habitat $C$. quinoa showed intermediate values, with the wild $C$. 163 hircinum always less productive than the cultivated C. quinoa, essentially due to lower aboveground growth. These 164 differences in seedling growth among the studied populations were in relation with their respective mean seed 165 mass (SM, Table 2). Despite contrasted growth capacities, C. pallidicaule and dry-habitat C. quinoa showed 166 similar biomass allocation patterns with R:S ratios of 0.31 and 0.28 respectively, significantly lower than those 167 observed in wet-habitat C. quinoa (0.45) and C. hircinum (0.39).

168 Root system profile and branching dynamics

169 After six weeks of plant growth (42 DAS), the vertical distribution of the root system showed significant 170 differences among populations and among soil layers (Fig. 3). In each soil layer, the number of root tips was highly 171 correlated to the root length $(\mathrm{r}=0.97, \mathrm{P}<0.001, \mathrm{n}=24)$ and both traits showed similar vertical distributions. $C$. 172 quinoa from dry and wet habitats had similar root profiles down to $65 \mathrm{~cm}$ depth, with maximum root development 173 in the 20-35 cm soil layer ( $c a .5 \mathrm{~m}$ root length in that layer, equivalent to a root length density $\mathrm{ca} .0 .35 \mathrm{~cm} \mathrm{root} / \mathrm{cm}^{3}$ 174 soil). Beyond a $65 \mathrm{~cm}$ depth, dry-habitat $C$. quinoa showed significantly higher root colonization than the wet175 habitat ecotype ( $c a .4 \mathrm{~m}$ of root against $0.5 \mathrm{~m}$ respectively). Compared to C. quinoa, C. hircinum and $C$. 176 pallidicaule showed significantly less root development, although the former still colonized deep soil while the 177 latter was almost exclusively limited to the $35-50 \mathrm{~cm}$ layer (Fig. 3).

178 These patterns of vertical root distribution at 42 DAS resulted from the progressive proliferation of the 179 root system through the soil profile (Fig. 1). The sequential analysis of the number of new lateral branches 180 appearing on the taproot during the experiment revealed contrasted dynamics among the studied populations (Fig. 181 4). In C. hircinum and wet-habitat C. quinoa, root branching proceeded in a similar way, with new lateral roots 182 successively appearing in ever deeper soil layers down to $75 \mathrm{~cm}$ at 42 DAS. The main difference between these 183 two populations was in a more extended period of root proliferation in wet-habitat $C$. quinoa, starting one week 
earlier than in C. hircinum. By contrast, in dry-habitat C. quinoa, root branching was maximum at $75 \mathrm{~cm}$ as soon as 35 DAS, when none of the other populations add reached that depth yet. In C. pallidicaule, root branching occurred over the same lapse of time than in the other populations but at a much lower rate, and it hardly passed the $30 \mathrm{~cm}$ soil depth.

188 Root segment and root system morphology

189 The morphology of individual root segments varied greatly among the studied populations, with SRL in $C$. pallidicaule showing roots three-fold finer on average than those of dry-habitat C. quinoa, the other two populations having intermediate values (Table 2). With regard to the shape of the root system, the topological slope index TSI showed statistical differences only among dry-habitat $C$. quinoa (0.72) and C. hircinum (0.87), while the topological quotient index TQI did not show any difference among the four populations (Table 2). Such high values of the topological indices are characteristic of a herringbone morphology for the root systems. The regression of $\log (\alpha)$ on $\log (\mu)$ showed a strong, unique linear relationship $\left(\mathrm{r}^{2}=0.96\right)$ over the range of observed plant sizes, irrespective of the species (Fig. 5). However, the plot also shows a tendency for the slope of the regression to decrease sharply at high magnitude values (namely, $\log (\mu)$ close to 3 ).

Root system architecture

Despite a similar herringbone morphology, the studied populations differed greatly in the details of their root system architecture: both $C$. quinoa ecotypes produced higher TRL and had significantly greater TLN and TTN than $C$. hircinum which, in turn, showed nearly three times more root branches and root tips than C. pallidicaule (Table 2).

A thorough analysis of the different kinds of root links reveals contrasted dynamics of root branching among the studied populations (Figs. 6, 7, 8). Except in the first three weeks when the root system was essentially limited to the taproot (see Fig. 1), EI links concentrated most of the total root length in the four populations (Fig. 6). Considering the cumulated root length per link type, the highest increase was observed between 28 and 35 DAS in dry-habitat $C$. quinoa, particularly in EI links which, by the end of the experiment, totalized $8 \mathrm{~m}$ per plant on average (53\% of the total root length) (Fig. 6). In comparison, EI links in C. pallidicaule at the same stage totalized only $2 \mathrm{~m}$ per plant on average, though they amounted to a similar proportion of the total root length. Decomposing the total root length in its two components (namely: the mean number and the mean length of the different links,

211 Fig. 7 and 8), it appeared that temporal changes in total root length reflected mostly the changes in link number (r $212=0.84, \mathrm{P}<0.001, \mathrm{n}=65)$ and not those in mean link length $(\mathrm{r}=0.02, \mathrm{P}>0.1, \mathrm{n}=65)$. The number of EI and EE 213 links increased progressively from 14 DAS on, with EI links always in a higher proportion than EE links in all 214 populations (Fig. 7). The appearance of new links reached its highest rate by the end of the experiment with wethabitat $C$. quinoa showing the highest rate of root branching.

Regarding the mean length of the different types of links, considerable variation was shown with maximal values of nearly $7 \mathrm{~cm}$ observed in the young taproot of the dry-habitat $C$. quinoa, while the taproot of the other populations was limited to about $2 \mathrm{~cm}$ at that early developmental stage (Fig. 8). From 14 DAS on, the mean length of II links decreased rapidly as a consequence of the emergence of new lateral roots. While mean link length did not show much time variations from 28 DAS on, it varied significantly among populations, with constantly longer II and EI links in dry-habitat C. quinoa than in the other three populations (Fig. 8 and Table 2). This trait 
compensated for lower or equal link numbers in this ecotype compared to that from wet habitat (Fig. 7 and Table 2), resulting in higher TRL in the dry-habitat $C$. quinoa, with a non-significant trend when considering the whole plant root system (Table 2, $\mathrm{P}=0.12$ ) but a highly significant difference as regards the cumulated EI segments (Fig. $6, \mathrm{P}<0.001)$ which formed the major part of the entire root system.

\section{Discussion}

227 Root topology in different chenopod species: plant size and ontogenetic effects

228 This study found significant variation in initial seedling size (TPM or PH, Table 2) among three Andean Chenopodium species, with $C$. quinoa producing two to five-fold more biomass than $C$. hircinum and up to fifteenfold more than $C$. pallicaule. Among the two $C$. quinoa ecotypes, the one from the dry habitat showed the most vigorous growth, which should give it a decisive advantage since initial seedling size strongly determines early plant survival in arid environments (León et al. 2010). As observed in other wild and cultivated species (Coomes and Grubb 2003; Bertholdsson et al. 2009), the ranking in plant vigor among the studied populations was related to the differences in individual seed mass. This contrast between species did not affect the overall shape of the root system: all showed similar root topological indices (Table 2) with values characteristic of herringbone root systems, a feature commonly observed in chenopod species (Fitter 1987). Such similar topological indices could reflect the phylogenetic closeness of the studied species. In fact, $C$. quinoa was probably domesticated from $C$. hircinum, this latter being also a wild relative of C. pallidicaule (Gandarillas 1984). An alternative explanation to this topological similarity arises when comparing our results to those of Glimskär (2000). In his study on forbs and grasses grown at different nitrogen levels, a quite general relationship emerges between altitude $(\alpha)$ and magnitude $(\mu)$ with a curvature in the $\log (\alpha) / \log (\mu)$ relation suggesting a general size effect. Interestingly, the curvature in Glimskär's data appears at $\log (\mu)$ near 3, with $\log (\alpha)$ leveling near 2.4, both values which are quite close to our own data for three chenopod species (Fig. 5). The leveling in the altitude / magnitude relationship as plants grow could have an ontogenetic explanation related to the continued branching of a not strictly herringbone root system. After an initial period of seedling growth dominated by the elongation and branching of the main root, lateral roots begin to emerge from internal links, thus forming new external links (EI) which directly increase the root system magnitude without necessarily increasing its altitude. In our study, such new lateral roots of second and higher orders emerged in great number from 21 DAS on (Figs. 4 and 7). The generality of the altitude / magnitude relation observed in forbs and grasses under different growth conditions (Arredondo and Jonhson 1991; Fitter 1991; Glimskär 2000; Paula et al. 2011; Roumet et al. 2006; this study), suggests a general ontogenetic shift in the root topology of annual plant species, with lateral roots emerging in ever greater numbers (increasing magnitude) as soon as $\log (\alpha)$ exceeds a value of 2 approximately.

Due to this ontogenetic effect, the curvature in the altitude / magnitude relation points to a limitation of the topological slope index (TSI) as proposed by Fitter and Stickland (1991). Assuming a linear relation over a large size range, TSI overemphasizes small deviations from linearity (Glimskär 2000), which makes it a poorly suited index to discriminate root branching patterns in growing seedlings (Paula and Pausas 2011). As an alternative index, Glimskär (2000) proposed the TQI quotient calculated on individual plants, with a range of values from 0.69 to 0.79 for five different species. Our chenopod species fall within this range with an estimate of 0.77 (Table 2). Considering our results together with those of Glimskär, we suggest a general ontogenetic shift as 
a possible component of this size effect. Therefore, when evaluating species differences in root topology, we would recommend comparing not only plants belonging to a narrow size interval (Glimskär 2000), but also plants of similar developmental stages.

As for the ecological interpretation of this ontogenetic-size effect on root topology, Glimskär (2000) as well as Paula and Pausas (2011) put forward that the more herringbone topology of young plants could be related to the need to quickly reach deep soil layers, in a context of competition with other plants. This assumption similarly applies to the growth of seedling plants in low-resource habitats where fast root growth at an early developmental stage would secure soil resource capture and young plant survival (León et al. 2011; Palta et al. 2011; Richards et al. 2007). The following discussion on the root foraging traits observed in the studied species brings more insights into this assumption.

Root foraging: a suite of traits significantly improved in the dry-habitat quinoa ecotype

While the herringbone topology remained virtually unchanged among the three Andean chenopods of the present study, their root systems were quite different with regard to the branching architecture and the progressive proliferation through the soil profile. C. quinoa produced higher total root length than $C$. hircinum and $C$. pallidicaule, though the difference between the $C$. hircinum and wet-habitat $C$. quinoa appeared marginal (Table 2). The detailed analysis of root links revealed that external links (EI and EE) were not only in higher proportion than internal links: they were also more abundant in wet-habitat $C$. quinoa and longer in dry-habitat $C$. quinoa than in the other two species (Table 2, Figs. 7 and 8). As these external links are more absorptive than the suberified internal root segments (Kramer and Boyer 1995), their relative abundance in C. quinoa should give this species a physiological advantage for soil resource uptake.

Among the $C$. quinoa populations, the one from the dry habitat had statistically fewer root tips and marginally fewer root links (Table 2) but consistently greater II and EI link lengths (Table 2, Fig. 8), resulting in marginally higher TRL values. Such compensation between link number and link length bears a general ecological significance as shown by Nicotra et al. (2002) who found, comparing 11 phylogenetically independent contrasts, that species originating from dry environments usually have fewer root links but with greater link length than species from wetter environments. From a functional point of view, greater root link length reduces the overlap between depletion zones of neighbouring branches and, thus, improves the root foraging efficiency particularly for mobile resources like nitrate or water (Arredondo and Johnson 2011; Fitter et al. 1991b; Pagès 2011). In arid habitats where soil water recharge occurs during the wet season and where deeper soil layers maintain higher soil moisture, a fast elongation of the root system at depth seems more adapted to drought than multiplying root branches in the upper soil layers (Bauerle et al. 2008; Padilla and Pugnaire 2007; Reader et al. 1993). The vertical root growth allows the plants to access water resources at depth, while dense root colonization in the upper soil would rapidly lead to root competition and complete water depletion in the absence of new rainfall events. For the plant mineral nutrition, however, a dense root system in the superficial layers, where soil nutrients generally accumulate, seems more favorable. In fact, most part of the root system in the three studied species was concentrated between 5 and $50 \mathrm{~cm}$ depth, with a maximum in the 20-35 cm soil layer (Fig. 3). But in the filtrating sandy soils typical of many arid and semi-arid areas, such a mobile element as nitrate moves easily to depth (Austin et al. 2004). In this case, a dense and fast root growth beyond $50 \mathrm{~cm}$ depth would be useful to better capture water as well as nitrate before they move beyond the root zone (Richards et al. 2007). This feature was indeed observed 
in the dry-habitat $C$. quinoa which produced abundant lateral roots at $75 \mathrm{~cm}$ depth as early as the fifth week of growth, when none of the other populations had reached that depth yet (Figs. 1b and 4). These observations substantiate those made in an independent experiment conducted on the same species, where dry-habitat $C$. quinoa reached $1 \mathrm{~m}$ taproot length between 42 and 49 DAS, one to two weeks earlier than wet-habitat $C$. quinoa and $C$. hircinum, while C. pallidicaule remained limited to the first $40 \mathrm{~cm}$ soil layer (Alvarez-Flores et al. 2014).

Differences in root architecture among populations from dry and wet habitats suggest an adaptive response of the plants for soil resource capture by means of an improved foraging capacity of the root system in the dry-habitat populations (Reynolds et al. 2004). In fact, the greater root link length in dry-habitat C. quinoa, particularly at the very beginning of the root system growth (Fig. 8), was associated with a fast and vigorous growth of the taproot in the early days after seed germination, then relayed by greater elongation of II and EI links in the subsequent weeks (Fig. 6). This elongation dynamics associated to a vigorous root branching at depth (Figs. $1 \mathrm{~b}$ and 4) explains how the dry-habitat $C$. quinoa rapidly developed a higher root foraging capacity than the wethabitat ecotype. In several wild and cultivated species, fast and vigorous rooting at depth was found crucial for early seedling survival in environments where water and nutrients are scarce and variable (León et al. 2011; Singh et al. 2010). In the most arid Andean highlands, quinoa farmers take advantage of this rooting pattern: traditionnally, quinoa fields in these rainfed agrosystems are sown every other year, and only seedlings with a vigorous foraging capacity are able to reach the water stored at depth during the fallow year preceeding the crop year (Joffre and Acho 2008).

Specific root length is another trait of importance for root foraging capacity, as it influences the capacity of the root system to proliferate through the soil, with thick roots (low SRL) penetrating more easily than fine ones, specially into dry or compacted soil layers (Cornelissen et al. 2003). In a comparison of nine shrub species of the Atacama desert, low SRL appeared linked to higher seedling survival rate (Léon et al. 2010). In general, low SRL values are characteristic of species from dry habitats that tend to have a conservative strategy of water use, with a lower absorptive surface per unit of root biomass (Nicotra et al. 2002; Wright and Westoby 1999). Low SRL in $C$. quinoa should thus enhance its ability to penetrate deeply tough soil layers and withstand low soil moisture, at the same time that it improves the anchoring of plants significantly taller than those of $C$. hircinum and $C$. pallidicaule (see PH and RCD values in Table 2). On the opposite, high SRL in C. pallidicaule could compensate for its low rooting capacity by a higher nutrient transport efficiency and relative low investment in root dry matter (Picon-Cochard et al. 2012). High SRL associated to the small plant height and low plant productivity typical of $C$. pallidicaule could be part of a plant growth syndrome adapted to cold, high altitude habitats where shallow soils supply only limited water and nutrient resources (Gade 1970; Poorter et al. 2011).

\section{Conclusion and perspectives}

331 The present study brings the first detailed report of root system architecture and growth dynamics in three little332 known Andean species of Chenopodium, including two cultivated ecotypes of C. quinoa. As a whole, the fast root 333 elongation, with thicker roots allowing deep soil penetration, and abundant and long external links conferring an efficient soil exploration, make a suite of root traits that significantly improve the root foraging capacity of $C$. quinoa compared to C. hircinum and C. pallidicaule. This should be particularly true for the dry-habitat C. quinoa, which showed the highest ranking in these root foraging traits, and which actually thrives in a region of poor but frequently deep sandy soils under extremely dry and cold climate. As for C. pallidicaule, it exhibited a particular 
plant growth syndrome adapted to shallow soils at very high altitude. In both situations, specific suites of architectural root traits are expressed from very early developmental stages to support initial seedling growth and establishment which are crucial for field performance. These contrasted rooting syndromes agree with two differential foraging strategies in dry environments described by several authors, namely: shallow root systems exploring topsoil layers to beneficiate from seasonal rainfalls, versus deep root systems with thick roots feeding from water stored at depth (Bauerle et al. 2008; Paula and Pausas 2011).

These findings identify some key root system attributes of the studied chenopods, particularly of $C$. quinoa which, despite growing scientific and economic interest (Rojas et al. 2009), remains up to now roughly parameterized in the few crop models developed for this species (see AquaCrop by Geerts et al. 2007, or STICS by Lebonvallet 2008). The integration of these root parameters into plant growth models could allow for a more accurate description and understanding of the different capacities of root foraging and nutrient uptake in the related species or ecotypes (Pagès 2011). Similarly, such root traits could be exploited in breeding for drought adaptation or low-input agriculture, though this would require some complementary studies to verify whether improved seedling root attributes translate into improved performance of mature plants in the field (Manshadi et al. 2008; Singh et al. 2010).

From an evolutionary perspective, one should bear in mind that natural selection as well as crop domestication both rely on phenotypic selection (Lynch and Brown 2012). Considering that the higher root branching and foraging capacity of $C$. quinoa is associated to a higher seed mass and higher biomass production than in its wild progenitor, C. hircinum, or its diploid relative, C. pallidicaule, we hypothesize that these root system traits have been indirectly selected during the polyploidization and domestication processes. Recent works on improved root systems in water-limited crops suggest that such indirect impacts on root branching and foraging might indeed have occurred in several crop species (Palta et al. 2011; Wasson et al. 2012).

Acknowledgments This research was funded by a PhD grant of the "Capital Humano Avanzado" programme of CONICYT-CHILE and by the ANR (Agence Nationale de la Recherche - The French National Research Agency) under the "Programme Agriculture et Développement Durable", project "ANR-06-PADD-011, EQUECO". We thank the staff of the "Plate-Forme d'Analyses Chimiques - PACE" and the Experimental Field of CEFE. We are most grateful to Felix Mamani Reynoso and Alejandro Bonifacio (UMSA, La Paz, Bolivia) for kindly providing the seeds of C. pallidicaule and C. hircinum, and to Ivan Prieto, Marie-Laure Navas and Florence Volaire for their constructive comments.

\section{References}

Alvarez-Flores R, Winkel T, Degueldre D, Del Castillo C, Joffre R (2014) Plant growth dynamics and root morphology of little-known species of Chenopodium from contrasted Andean habitats. Botany 92: 101108

Alvear M., Rosas A., Rouanet JL, Borie F (2005) Effects of three soil tillage systems on some biological activities in an Ultisol from southern Chile. Soil Tillage Res. 82: 195-202

Arredondo JT, Johnson DA (1999) Root architecture and biomass allocation of three range grasses in response to nonuniform supply of nutrients and shoot defoliation. New Phytologist 143: 373-385 functional traits in three range grasses. Journal of Experimental Botany 62: 5581-5594 
Austin AT, Yahdjian L, Stark JM, Belnap J, Porporato A, Norton U, Ravetta DA, Schaeffer SM (2004) Water pulses and biogeochemical cycles in arid and semiarid ecosystems. Oecologia 141: 221-235

Bauerle TL, Smart DR, Bauerle WL, Stockert C, Eissenstat DM (2008) Root foraging in response to heterogeneous soil moisture in two grapevines that differ in potential growth rate. New Phytologist 179: 857-866

Bhargava A, Shukla S, Rajan S, Ohri D (2007) Genetic diversity for morphological and quality traits in quinoa (Chenopodium quinoa Willd.) germplasm. Genetic Resources and Crop Evolution 54: 167-173

Berntson GM (1994) Modelling root architecture: are there tradeoffs between efficiency and potential of resource acquisition? New Phytologist 127: 483-493

Bertholdsson NO, Kolodinska Brantestam A (2009) A century of Nordic barley breeding: effects on early vigour root and shoot growth, straw length, harvest index and grain weight. European Journal of Agronomy 30: 266-274

Bonifacio A (2003) Chenopodium sp.: genetic resources, ethnobotany, and geographic distribution. Food Reviews International 19: 1-7

Coomes DA, Grubb PJ (2003) Colonization, tolerance, competition and seed-size variation within functional groups. Trends in Ecology and Evolution 18: 283-291

Cornelissen JHC, Lavorel S, Garnier E, Díaz S, Buchmann N, Gurvich DE, Reich PB, ter Steege H, Morgan HD, van der Heijden MGA, Pausas JG, Poorter H (2003) A handbook of protocols for standardised and easy measurement of plant functional traits worldwide. Australian Journal of Botany 51: 335-380

De Dorlodot S, Forster B, Pagès L, Price A, Tuberosa R, Draye X (2007) Root system architecture: opportunities and constraints for genetic improvement of crops. Trends in Plant Science 12: 474-481

Di Castri F, Hajek ER (1976) Bioclimatología de Chile. Vicerrectoría Académica de la Universidad Católica de Chile. Santiago, Chile.

Fitter AH (1987) An architectural approach to the comparative ecology of plant root systems. New Phytologist 106: 61-77

Fitter AH, Stickland TR (1991) Architectural analysis of plant root systems 2. Influence of nutrient supply on architecture in contrasting plant species. New Phytologist 118: 383-389

Fitter AH, Stickland TR, Harvey ML, Wilson GW (1991) Architectural analysis of plant root systems. 1. Architectural correlates of exploitation efficiency. New Phytologist 118: 375-382

Gade DW (1970) Ethnobotany of canihua (Chenopodium pallidicaule), rustic seed crop of altiplano. Economic Botany 24:55-61

Gandarillas H. (1984) Obtención experimental de Chenopodium quinoa Willd. MACA, IBTA. La Paz, Bolivia.

Geerts S, Raes D, Garcia M, Del Castillo C, Buytaert W (2006) Agro-climatic suitability mapping for crop production in the Bolivian Altiplano: a case study for quinoa. Agricultural and Forest Meteorology 139: $399-412$

Geerts S, Raes D, Garcia M, Miranda R, Cusicanqui JA, Taboada C, Mendoza J, Huanca R, Mamani A, Condori O, Mamani J, Morales B, Osco V, Steduto P (2009) Simulating yield response of quinoa to water availability with AquaCrop. Agronomy Journal 101: 499-508

Glimskär A (2000) Estimates of root system topology of five plant species grown at steady-state nutrition. Plant and Soil 227: 249-256

Joffre R, Acho J (2008). Quinua, descanso y tholares en el sur del Altiplano Boliviano. Habitat 75: 38-41 
Kashiwagi J, Krishnamurthy L, Crouch JH, Serraj R (2006) Variability of root length density and its contributions to seed yield in chickpea (Cicer arietinum L.) under terminal drought stress. Field Crops Research 95: $171-181$

Kramer PJ, Boyer JS (1995) Water relations of plants and soils. San Diego, USA: Academic Press

Kühn U, Bittrich V, Carolin R, Freitag H, Hedge IC, Uotila P, Wilson PG (1993) Chenopodiaceae. In: Kubitzki K, Rohwer JG, Bittrich V, eds. The families and genera of vascular plants. Volume II: Flowering plants, Dicotyledons. Springer Verlag. Berlin, Germany. 253-281

Lebonvallet S (2008) Implantation du quinoa et simulation de sa culture sur l'altiplano bolivien. Thèse de Doctorat. Ecole Doctorale ABIES, AgroParisTech, Paris, France: 244 p.

León MF, Squeo FA, Gutiérrez JR, Holmgren M (2011) Rapid root extension during water pulses enhances establishment of shrub seedlings in the Atacama Desert. Journal of Vegetation Science 22: 120-129

Leva PE, Aguiar MR, Oesterheld M (2009) Underground ecology in a Patagonian steppe: Root traits permit identification of graminoid species and classification into functional types. Journal of Arid Environments 73: $428-434$

Liu L, Gan Y, Bueckert R, Van Rees K (2011) Rooting systems of oilseed and pulse crops I: Temporal growth patterns across the plant developmental periods. Field Crops Research 122: 256-263

Lynch JP, Brown KM (2012) New roots for agriculture: exploiting the root phenome. Philosophical Transactions of the Royal Society B-Biological Sciences 367: 1598-1604

Manschadi A, Hammer G, Christopher J, deVoil P (2008) Genotypic variation in seedling root architectural traits and implications for drought adaptation in wheat (Triticum aestivum L.). Plant and Soil 303: 115-129

Gandarillas H. 1984. Obtención experimental de Chenopodium quinoa Willd. MACA, IBTA. La Paz, Bolivia. 21 p.

Nibau C, Gibbs DJ, Coates JC (2008) Branching out in new directions: the control of root architecture by lateral root formation. New Phytologist 179: 595-614

Nicotra AB, Babicka N, Westoby M (2002) Seedling root anatomy and morphology: an examination of ecological differentiation with rainfall using phylogenetically independent contrasts. Oecologia 130: 136-145

Padilla FM, Pugnaire FI (2007) Rooting depth and soil moisture control Mediterranean woody seedling survival

Pagès L (2011) Links between root developmental traits and foraging performance. Plant, Cell and Environment 34: $1749-1760$

Palta JA, Chen X, Milroy SP, Rebetzke GJ, Dreccer MF, Watt M (2011) Large root systems: are they useful in adapting wheat to dry environments? Functional Plant Biology 38: 347-354

Paula S, Pausas JG (2011) Root traits explain different foraging strategies between resprouting life histories. Oecologia 165: 321-331

Picon-Cochard C, Pilon R, Tarroux E, Pagès L, Robertson J, Dawson L (2012) Effect of species, root branching order and season on the root traits of 13 perennial grass species. Plant and Soil 353: 47-57

Poorter H, Niklas KJ, Reich PB, Oleksyn J, Poot P, Mommer L (2011) Biomass allocation to leaves, stems and roots: meta-analyses of interspecific variation and environmental control. New Phytol 193:30-50 depth in drying soil. Journal of Ecology 81: 543-550 
Reyes F, Lillo A, Ojeda N, Reyes M, Alvear M (2011) Efecto de la exposición y la toposecuencia sobre actividades biológicas del suelo en bosque relicto del centro-sur de Chile. Bosque 32: 255-265

Reynolds JF, Kemp PR, Ogle K, Fernández RJ (2004) Modifying the 'pulse-reserve' paradigm for deserts of North America: precipitation pulses, soil water, and plant responses. Oecologia 141: 194-210

Richards R, Watt M, Rebetzke G (2007) Physiological traits and cereal germplasm for sustainable agricultural systems. Euphytica 154: 409-425

Rojas W, Valdivia R, Padulosi S, Pinto M, Soto JL, Alcócer E, Guzmán L, Estrada R, Apaza V, Bravo R (2009) From neglect to limelight: issues, methods ans approaches in enhancing sustainable conservation and use of Andean grains in Bolivia and Peru. Journal of Agricultural and Rural Development in the Tropics and Subtropics 92: 87-117

Roumet C, Urcelay C, Díaz S (2006) Suites of root traits differ between annual and perennial species growing in the field. New Phytologist 170: 357-368

Singh V, van Oosterom EJ, Jordan DR, Messina CD, Cooper M, Hammer GL (2010) Morphological and architectural development of root systems in sorghum and maize. Plant and Soil 333: 287-299.

Taub DR, Goldberg D (1996) Root system topology of plants from habitats differing in soil resource availability. Functional Ecology 10: 258-264

Troll C, ed. (1968) Geo-ecology of the mountainous regions of the tropical Americas. Colloquium Geographicum, vol. 9. Ferd. Dümmlers Verlag. Bonn, Germany

Vargas A, Elzinga D, Rojas-Beltran J, Bonifacio A, Geary B, Stevens M, Jellen E, Maughan P (2011) Development and use of microsatellite markers for genetic diversity analysis of cañahua (Chenopodium pallidicaule Aellen). Genetic Resources and Crop Evolution 58: 727-739

Wasson AP et al. (2012) Traits and selection strategies to improve root systems and water uptake in water-limited wheat crops. Journal of Experimental Botany 63: 3485-3498

White PJ, George TS, Gregory PJ, Bengough AG, Hallett PD, McKenzie BM (2013) Matching roots to their environment. Annals of Botany 112: 207-222

Wright IJ, Westoby M (1999) Differences in seedling growth behaviour among species: trait correlations across species, and trait shifts along nutrient compared to rainfall gradients. Journal of Ecology 87: 85-97 


\section{LIST OF THE TABLES}

485

486 Table 1 Origin of the four studied Chenopodium populations.

487 Table 2 Mean values of seed mass, and plant and root system traits of four Chenopodium populations at 42 DAS.

488 SM: individual seed mass (mg/seed), TPM: total plant mass (g/plant), LA: leaf area ( $\left.\mathrm{cm}^{2} / \mathrm{plant}\right)$, PH: plant height 489 (cm), R:S: root shoot ratio (g/g), RCD: root collar diameter (mm), SRL: specific root length (m/g), TRL: total root 490 length (m/plant), TTN: total tip number, TLN: total link number, TQI: topological quotient index, TSI: topological 491 slope index, MLL: mean link length (II: Internal-Internal links, EI: External-Internal links, EE: External-External 492 links). (data show mean \pm standard error, $n=5$ except for SM $(n=120)$, different letters within a row show 493 significant differences at $\mathrm{P}=0.05$ ) 
Table 1 Origin of the four studied Chenopodium populations.

\begin{tabular}{lccccccc}
\hline Species & Code & Provenance & Latitude & Longitude & $\begin{array}{c}\text { Altitude } \\
(\mathbf{m})\end{array}$ & $\begin{array}{c}\text { Rainfall mean } \\
(\mathbf{m m} / \mathbf{y} \text { ear })\end{array}$ & $\begin{array}{c}\text { SOM range } \\
(\%)^{\mathrm{a}}\end{array}$ \\
\hline C. hircinum & HI & Aranjuez, Bolivia & $16^{\circ} 33^{\prime} \mathrm{S}$ & $68^{\circ} 36^{\prime} \mathrm{W}$ & 3.200 & 550 & $0.4-1.5$ \\
C. pallidicaule & PA & La Paz, Bolivia & $17^{\circ} 30^{\prime} \mathrm{S}$ & $68^{\circ} 36^{\prime} \mathrm{W}$ & 3.600 & 550 & $0.4-1.5$ \\
C. quinoa & QB & Jirira, Bolivia & $19^{\circ} 51^{\prime} \mathrm{S}$ & $67^{\circ} 34^{\prime} \mathrm{W}$ & 3.700 & 250 & $0.2-0.4$ \\
C. quinoa & QC & Cunco, Chile & $38^{\circ} 56^{\prime} \mathrm{S}$ & $72^{\circ} 03^{\prime} \mathrm{W}$ & 200 & 1.200 & $7-29$ \\
\hline
\end{tabular}

495 SOM: soil organic matter

496 a sources: HI, PA and QB: Lebonvallet (2008); QC: Alvear et al. (2005) and Reyes et al. (2011).

497

498 Table 2 Mean values of seed mass, and plant and root system traits of four Chenopodium populations at 42 DAS. 499 SM: individual seed mass (mg/seed), TPM: total plant mass (g/plant), LA: leaf area ( $\left.\mathrm{cm}^{2} / \mathrm{plant}\right)$, PH: plant height 500 (cm), R:S: root shoot ratio (g/g), RCD: root collar diameter (mm), SRL: specific root length (m/g), TRL: total root 501 length (m/plant), TTN: total tip number, TLN: total link number, TQI: topological quotient index, TSI: topological 502 slope index, MLL: mean link length (cm; II: Internal-Internal links, EI: External-Internal links, EE: External503 External links). (data show mean \pm standard error, $n=5$ except for SM $(n=120)$, different letters within a row 504 show significant differences at $\mathrm{P}=0.05$ ).

505

\begin{tabular}{lrrrr}
\hline Traits & $\begin{array}{r}\text { C. quinoa } \\
\text { (dry habitat) }\end{array}$ & $\begin{array}{r}\text { C. quinoa } \\
\text { (wet habitat) }\end{array}$ & C. hircinum & C. pallidicaule \\
\hline SM & $4.89 \pm 0.10 \mathrm{a}$ & $2.09 \pm 0.04 \mathrm{~b}$ & $1.50 \pm 0.04 \mathrm{c}$ & $0.6 \pm 0.01 \mathrm{~d}$ \\
TPM & $2.00 \pm 0.37 \mathrm{a}$ & $0.87 \pm 0.10 \mathrm{~b}$ & $0.40 \pm 0.08 \mathrm{c}$ & $0.13 \pm 0.03 \mathrm{~d}$ \\
LA & $98.0 \pm 3.7 \mathrm{a}$ & $54.0 \pm 1.3 \mathrm{~b}$ & $21.7 \pm 4.8 \mathrm{c}$ & $10.0 \pm 2.3 \mathrm{~d}$ \\
PH & $8.4 \pm 0.5 \mathrm{a}$ & $5.9 \pm 0.5 \mathrm{~b}$ & $4.5 \pm 0.4 \mathrm{bc}$ & $3.5 \pm 0.4 \mathrm{c}$ \\
R:S & $0.28 \pm 0.01 \mathrm{a}$ & $0.39 \pm 0.02 \mathrm{~b}$ & $0.45 \pm 0.01 \mathrm{c}$ & $0.31 \pm 0.03 \mathrm{ab}$ \\
RCD & $4.90 \pm 0.49 \mathrm{a}$ & $3.47 \pm 0.49 \mathrm{~b}$ & $2.31 \pm 0.28 \mathrm{c}$ & $1.34 \pm 0.27 \mathrm{~d}$ \\
SRL & $57.9 \pm 3.82 \mathrm{a}$ & $75.1 \pm 12.2 \mathrm{ab}$ & $106.5 \pm 10.0 \mathrm{~b}$ & $179.7 \pm 15.3 \mathrm{c}$ \\
TRL & $24.1 \pm 3.4 \mathrm{a}$ & $16.4 \pm 2.6 \mathrm{ab}$ & $12.7 \pm 2.0 \mathrm{~b}$ & $4.8 \pm 0.4 \mathrm{c}$ \\
TTN & $525 \pm 14.3 \mathrm{a}$ & $663 \pm 12.4 \mathrm{~b}$ & $449 \pm 11 \mathrm{c}$ & $140 \pm 8.1 \mathrm{~d}$ \\
TLN & $1122 \pm 64.6 \mathrm{a}$ & $1398 \pm 62 \mathrm{~b}$ & $816 \pm 61.2 \mathrm{c}$ & $283 \pm 46.1 \mathrm{~d}$ \\
TQI & $0.77 \pm 0.01 \mathrm{a}$ & $0.77 \pm 0.01 \mathrm{a}$ & $0.77 \pm 0.01 \mathrm{a}$ & $0.77 \pm 0.01 \mathrm{a}$ \\
TSI & $0.72 \pm 0.04 \mathrm{a}$ & $0.80 \pm 0.04 \mathrm{ab}$ & $0.87 \pm 0.03 \mathrm{~b}$ & $0.85 \pm 0.04 \mathrm{ab}$ \\
MLL II & $1.0 \pm 0.03 \mathrm{a}$ & $0.6 \pm 0.02 \mathrm{~b}$ & $0.5 \pm 0.01 \mathrm{c}$ & $0.6 \pm 0.03 \mathrm{~b}$ \\
MLL EI & $2.0 \pm 0.05 \mathrm{a}$ & $1.2 \pm 0.03 \mathrm{~b}$ & $1.7 \pm 0.04 \mathrm{c}$ & $1.6 \pm 0.08 \mathrm{c}$ \\
MLL EE & $1.7 \pm 0.09 \mathrm{a}$ & $1.8 \pm 0.11 \mathrm{a}$ & $1.8 \pm 0.15 \mathrm{a}$ & $2.4 \pm 0.28 \mathrm{~b}$ \\
\hline
\end{tabular}


509 Fig. 1 Time course of the root system growth of two typical plants of Chenopodium hircinum (above) and

510 Chenopodium quinoa from dry habitat (below) as observed in the rhizotron (DAS: days after sowing).

511 Fig. 2 Root system topology: (a) Link types: EE (External-External), EI (External-Internal), II (Internal-

512 Internal). (b) Maximally herringbone topology: magnitude = altitude $=8$. (c) Maximally dichotomic topology:

513 magnitude $=8$, altitude $=4$. In (b) and (c), the first number in each pair is the altitude from the root collar and the

514 second the link magnitude (modified from Arredondo and Johnson 1999).

515 Fig. 3 Total root length distribution in the soil profile at 42 DAS in dry-habitat $C$. quinoa (QB), wet-habitat $C$.

516 quinoa (QC), C. hircinum $(\mathrm{HI})$ and C. pallidicaule (PA) (mean \pm standard error, $\mathrm{n}=5$, letters show statistical

517 differences between populations at a given depth, $\mathrm{P}<0.05)$.

518 Fig. 4 Vertical distribution of the mean number of new lateral roots appearing on the taproot during the

519 experiment in dry-habitat C. quinoa (QB), wet-habitat C. quinoa (QC), C. hircinum (HI) and C. pallidicaule

520 (PA) (each point is the mean of $\mathrm{n}=5$ plants).

521 Fig. 5 Logarithmic regression of altitude $(\alpha)$ on magnitude $(\mu)$ of the root system observed during the experiment 522 in dry-habitat $C$. quinoa $(\triangle)$, wet-habitat $C$. quinoa $(\mathbf{\Delta}), C$. hircinum $(\mathbf{O})$ and $C$. pallidicaule $(\mathrm{O})(\mathrm{y}=0.81 \mathrm{x}+$ $5230.08, \mathrm{r}^{2}=0.96, \mathrm{n}=80$; the dotted line corresponds to a maximally herringbone topology; see Material and

524 Methods for definitions of altitude and magnitude).

525 Fig. 6 Mean cumulative length of the internal-internal (II), external-internal (EI) and external-external (EE) root 526 links per plant in the four studied Chenopodium populations (dry-habitat C. quinoa: black, wet-habitat $C$. quinoa 527 from wet habitat: dark grey, C. hircinum: light grey, C. pallidicaule: white) (n=5, vertical bars show standard

528 errors, insets show root length on a log scale for a better appreciation of changes at early stages, see Fig. 2 for the 529 definition of II, EI and EE links).

530 Fig. 7 Mean number of internal-internal (II), external-internal (EI) and external-external (EE) root links per plant 531 in four Chenopodium populations (same color chart as in Fig. 6) ( $\mathrm{n}=5$, vertical bars show standard errors, insets 532 show link number on a log scale for a better appreciation of changes at early stages, see Fig. 2 for the definition 533 of II, EI and EE links).

534 Fig. 8 Mean length of the internal-internal (II), external-internal (EI) and external-external (EE) root links in the 535 four studied Chenopodium populations (same color chart as in Fig. 7) $(n=5$, vertical bars show standard errors, 536 see Fig. 2 for the definition of II, EI and EE links). 

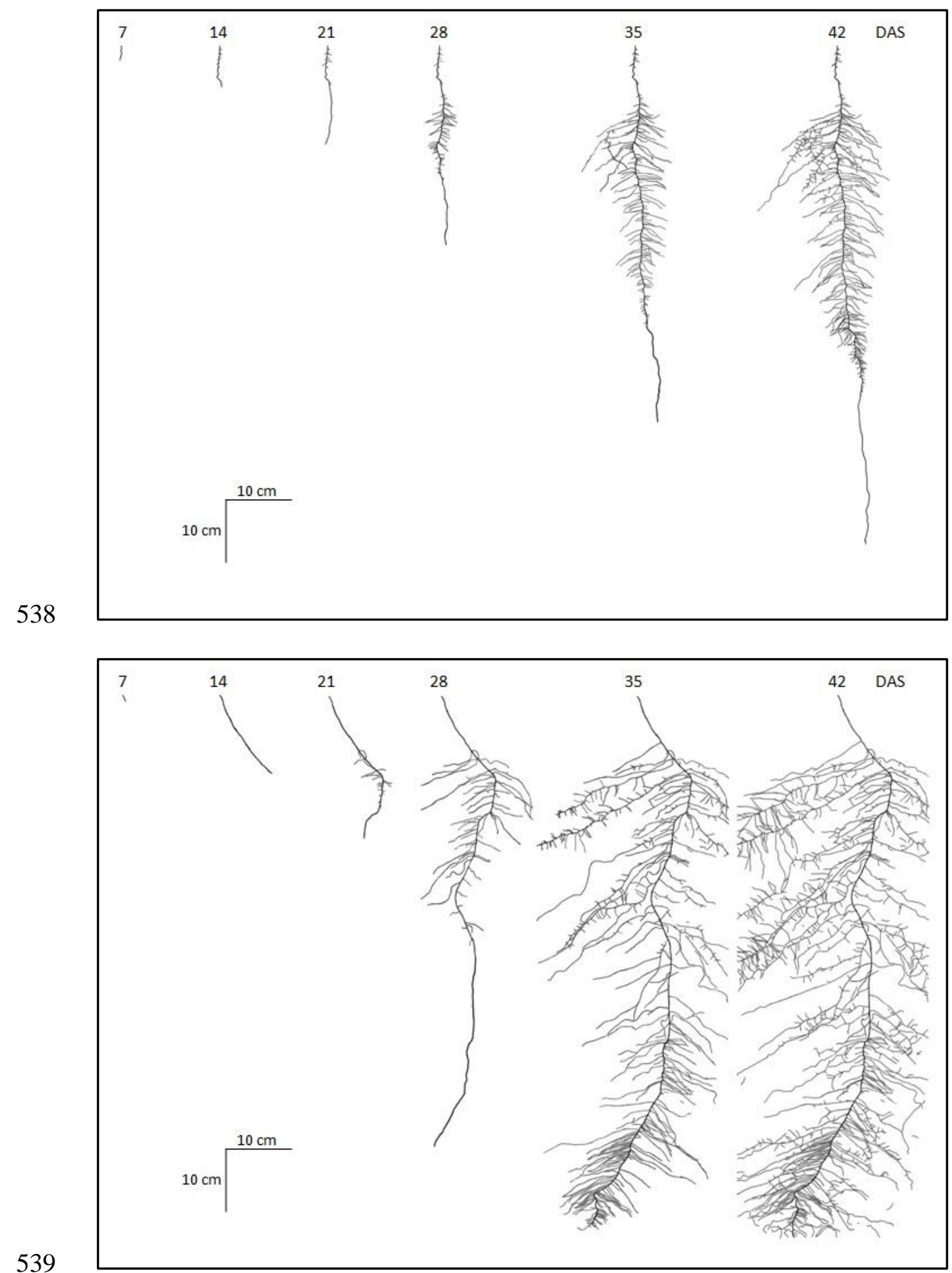

540 Fig. 1 Time course of the root system growth of two typical plants of Chenopodium hircinum (above) and dry541 habitat Chenopodium quinoa (below) as observed in the rhizotron (DAS: days after sowing). 


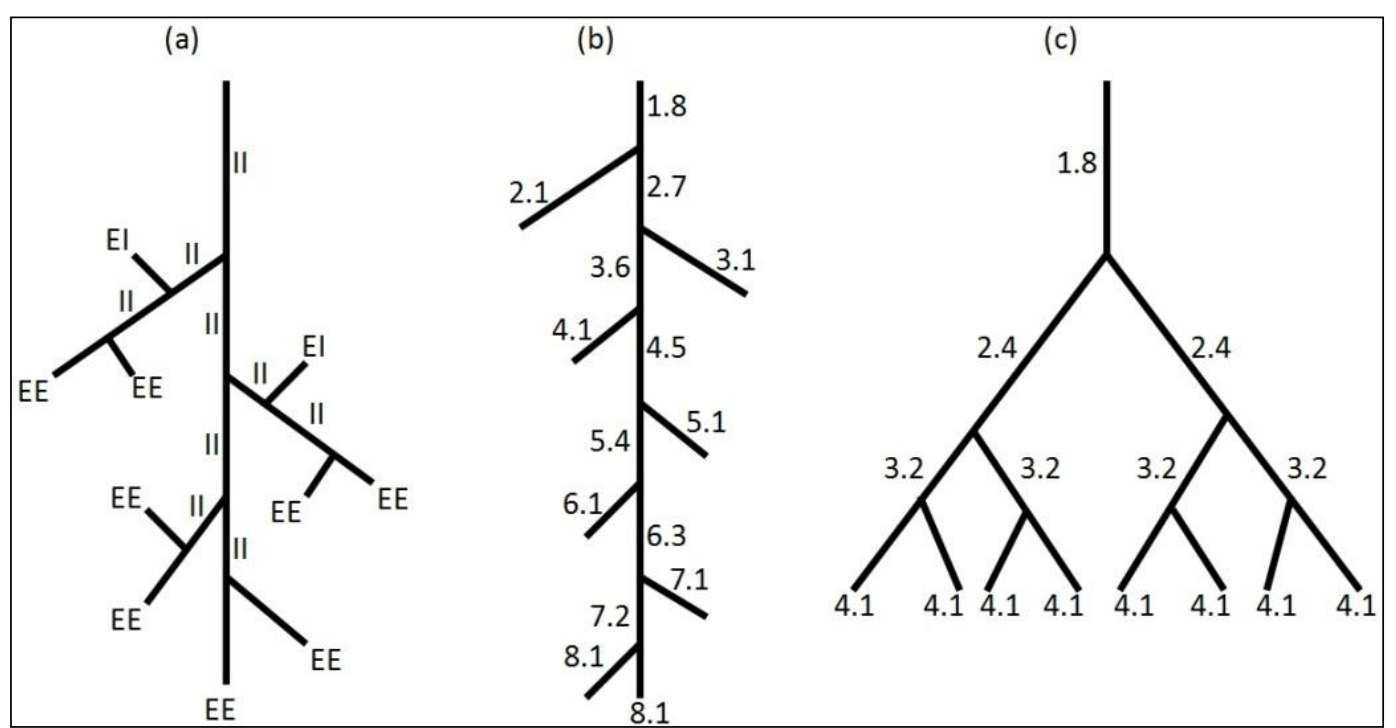

544 Fig. 2 Root system topology: (a) Link types: EE (External-External), EI (External-Internal), II (Internal-Internal).

545 (b) Maximally herringbone topology: magnitude $=$ altitude $=8$. (c) Maximally dichotomic topology: magnitude $=$ 5468 , altitude $=4$. In (b) and (c), the first number in each pair is the altitude from the root collar and the second the 547 link magnitude (modified from Arredondo and Johnson 1999). 


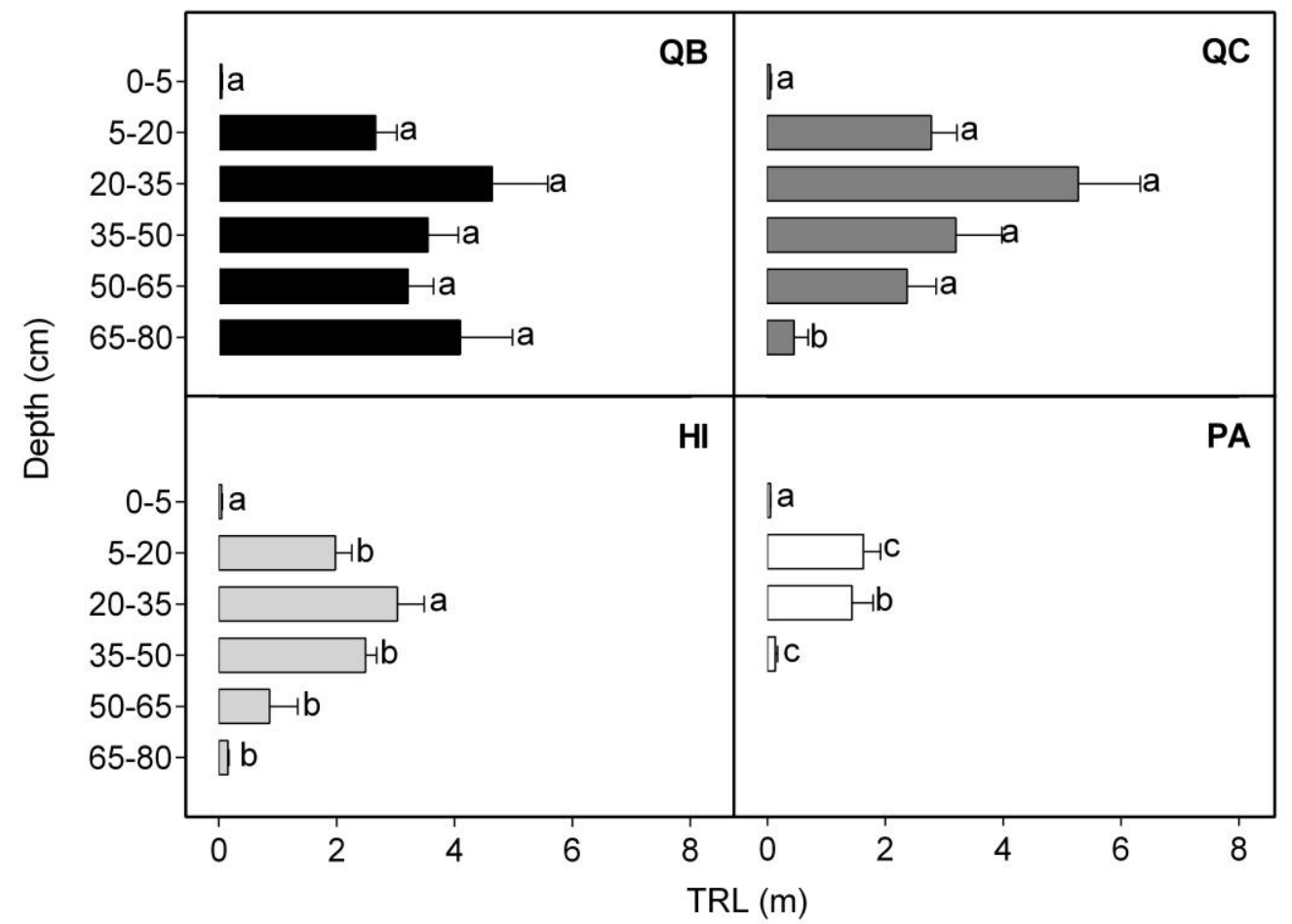

550 Fig. 3 Total root length distribution in the soil profile at 42 DAS in dry-habitat $C$. quinoa (QB), wet-habitat $C$. 551 quinoa (QC), C. hircinum (HI) and C. pallidicaule (PA) (mean \pm standard error, $\mathrm{n}=5$, letters show statistical 552 differences among populations at a given depth, $\mathrm{P}<0.05)$. 


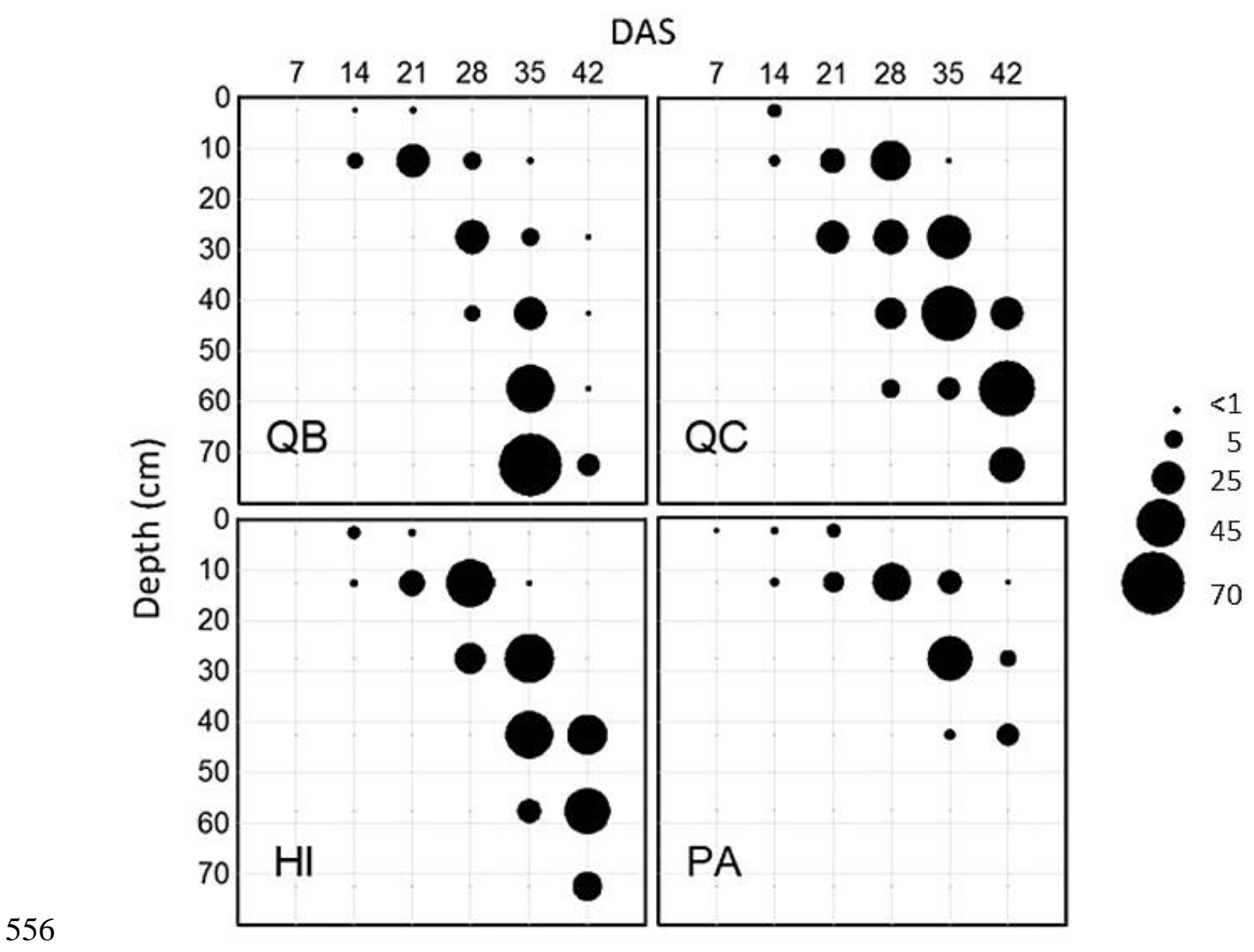

558 Fig. 4 Vertical distribution of the mean number of new lateral roots appearing on the taproot during the experiment 559 in dry-habitat C. quinoa (QB), wet-habitat C. quinoa (QC), C. hircinum (HI) and C. pallidicaule (PA) (each point 560 is the mean of $n=5$ plants). 


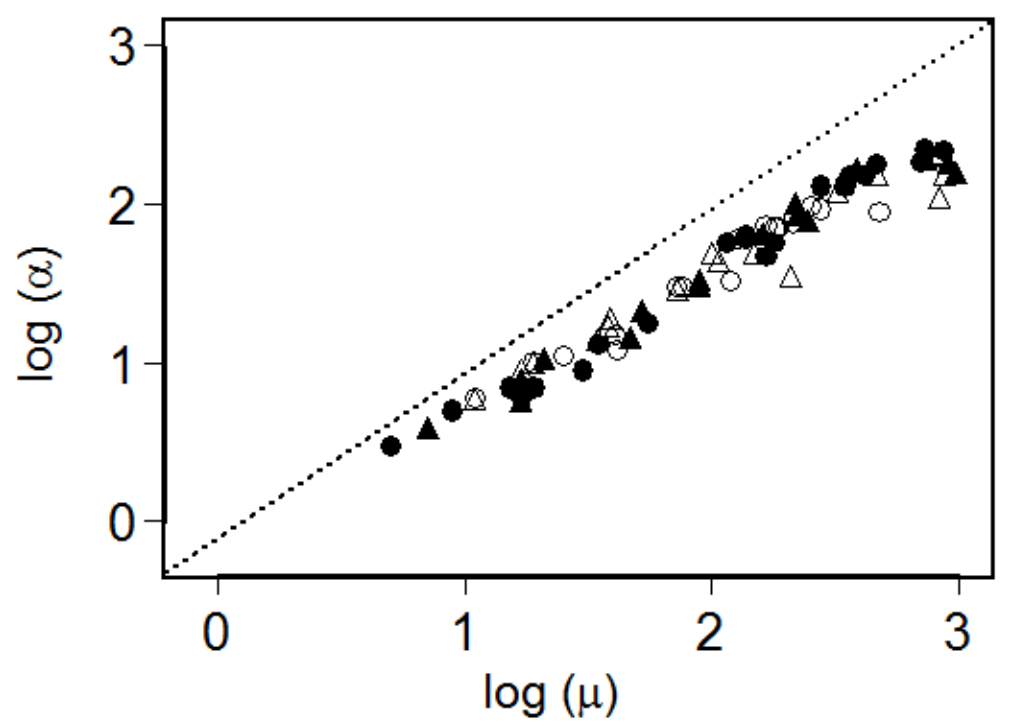

564

565 Fig. 5 Logarithmic regression of altitude $(\alpha)$ on magnitude $(\mu)$ of the root system observed during the experiment

566 in dry-habitat $C$. quinoa $(\triangle)$, wet-habitat $C$. quinoa $(\mathbf{\Delta})$, C. hircinum $(\bullet)$ and $C$. pallidicaule $(\mathrm{O})(\mathrm{y}=0.81 \mathrm{x}+$ $5670.08, \mathrm{r}^{2}=0.96, \mathrm{n}=80$; the dotted line corresponds to a maximally herringbone topology; see Material and Methods 568 for definitions of altitude and magnitude). 


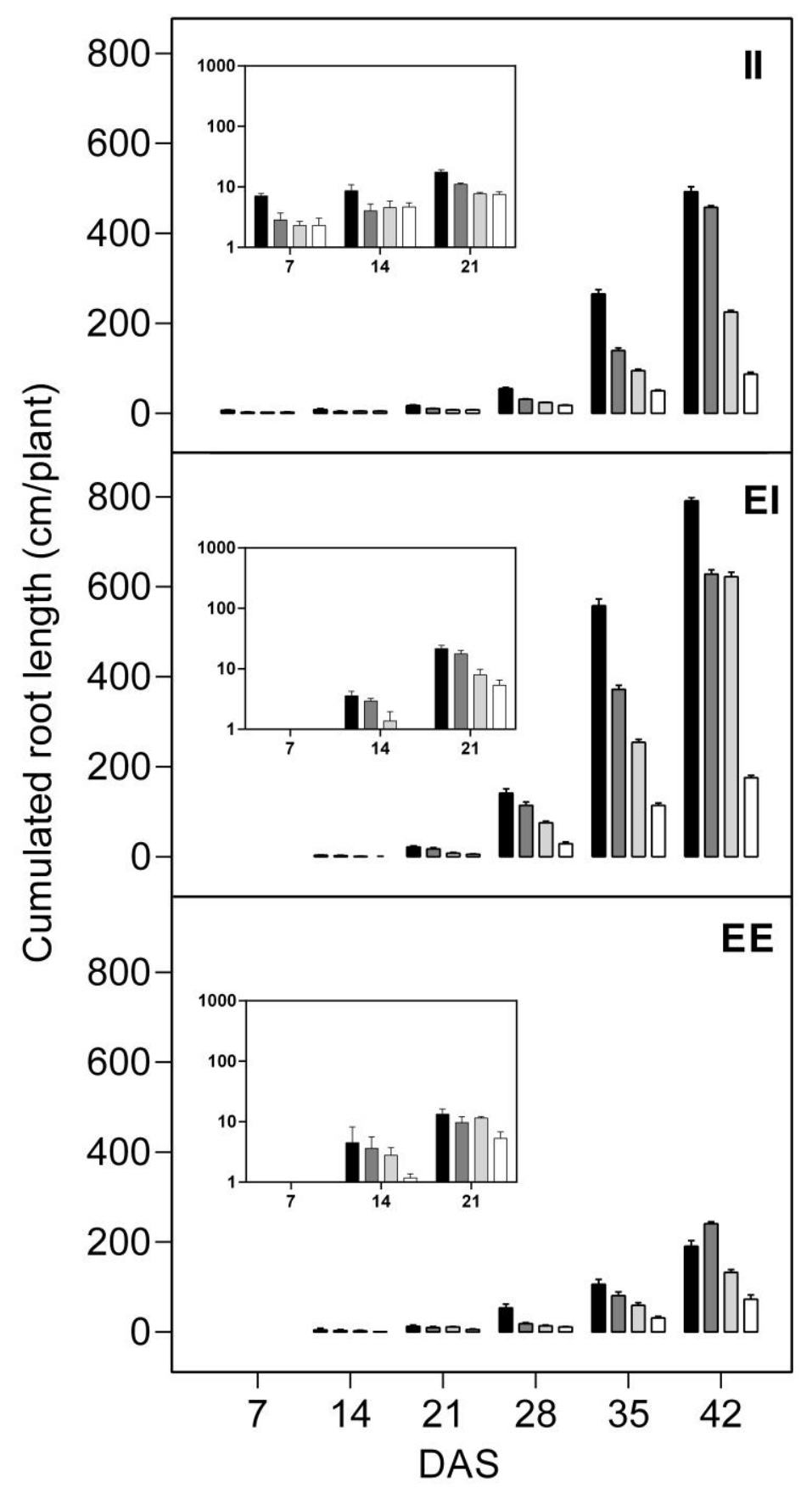

571 Fig. 6 Mean cumulative length of the internal-internal (II), external-internal (EI) and external-external (EE) root 572 links per plant in the four studied Chenopodium populations (dry-habitat C. quinoa: black, wet-habitat C. quinoa: 573 dark grey, C. hircinum: light grey, C. pallidicaule: white) ( $\mathrm{n}=5$, vertical bars show standard errors, insets show 574 root length on a log scale for a better appreciation of changes at early stages, see Fig. 2 for the definition of II, EI 575 and EE links). 


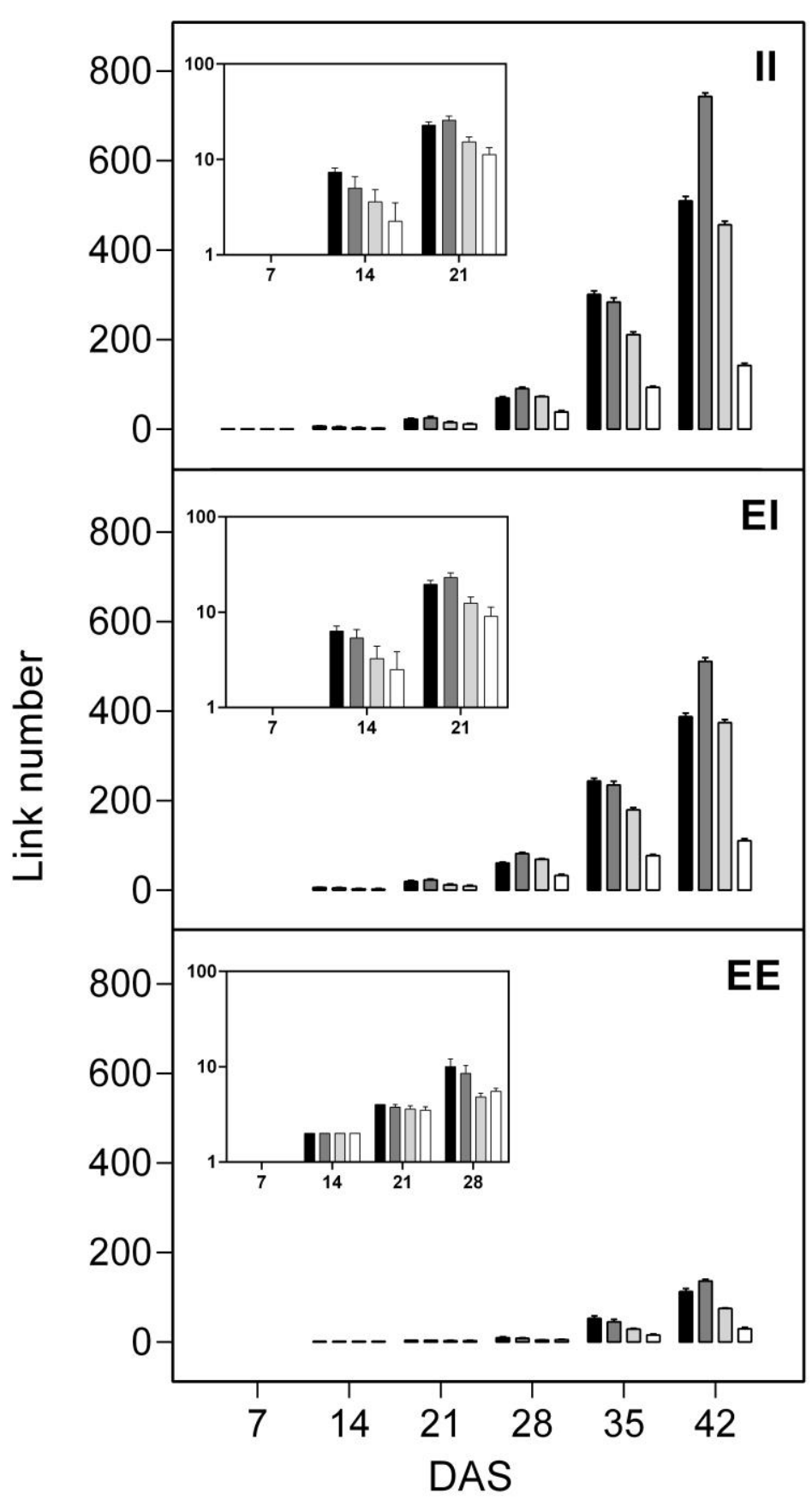

578 Fig. 7 Mean number of internal-internal (II), external-internal (EI) and external-external (EE) root links per plant 579 in four Chenopodium populations (same color chart as in Fig. 6) ( $n=5$, vertical bars show standard errors, insets 580 show link number on a log scale for a better appreciation of changes at early stages, see Fig. 2 for the definition of 581 II, EI and EE links). 


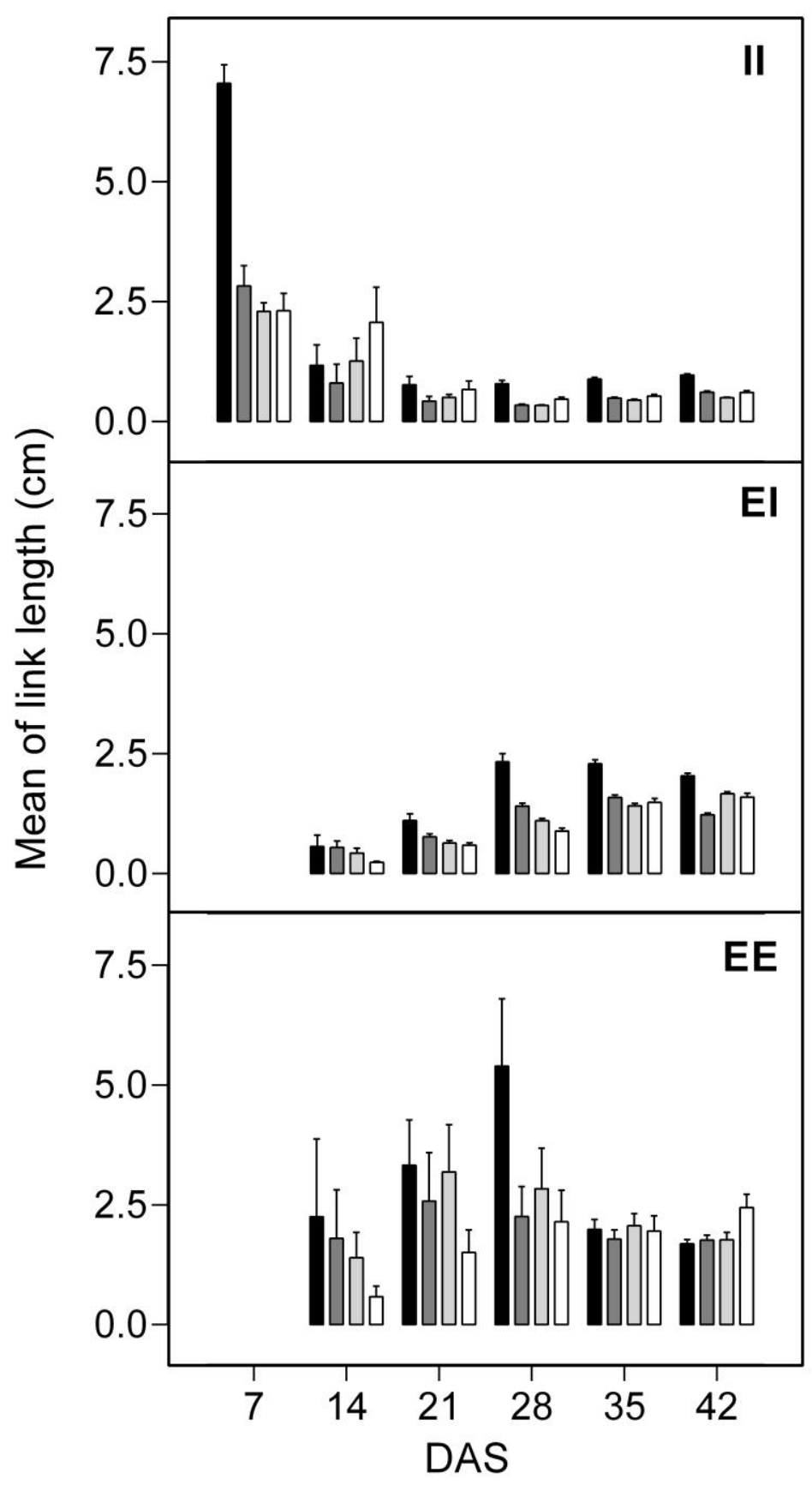

584 Fig. 8 Mean length of the internal-internal (II), external-internal (EI) and external-external (EE) root links in the 585 four studied Chenopodium populations (same color chart as in Fig. 6) $(n=5$, vertical bars show standard errors, 586 see Fig. 2 for the definition of II, EI and EE links). 